\title{
Metal matrix composites: Solidification parameters of aluminium-11.8\% silicon alloy reinforced with titanium carbide particulates.
}

\begin{abstract}
In this study, solidification analysis of metal matrix composite, aluminium-11.8\% silicon alloy matrix reinforced with titanium carbide particulates is performed. Sand casting method is used as the manufacturing method to produce the specimens. Thermal measurements during the casting process are captured and solidification graphs are plotted to represent the solidification characteristic. Solidification analysis is performed by interpreting the solidification graphs. Parameters such as; the nucleation of primary alpha phase temperature, liquidus arrest temperature, liquidus undercooling, eutectic growth temperature and solidification time are presented. The results show that introduction of second phase particulates into a matrix alloy have affected the various time and temperature parameters of its solidification properties.
\end{abstract}

Keyword: Aluminium alloy; Metal Matrix Composite (MMC); Solidification parameters; Titanium carbide particulates. 